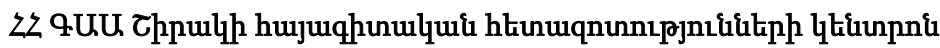

Ширакский центр арменоведческих исследований НАН РА

Shirak Centre of Armenological Studies NAS RA

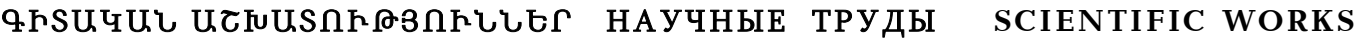

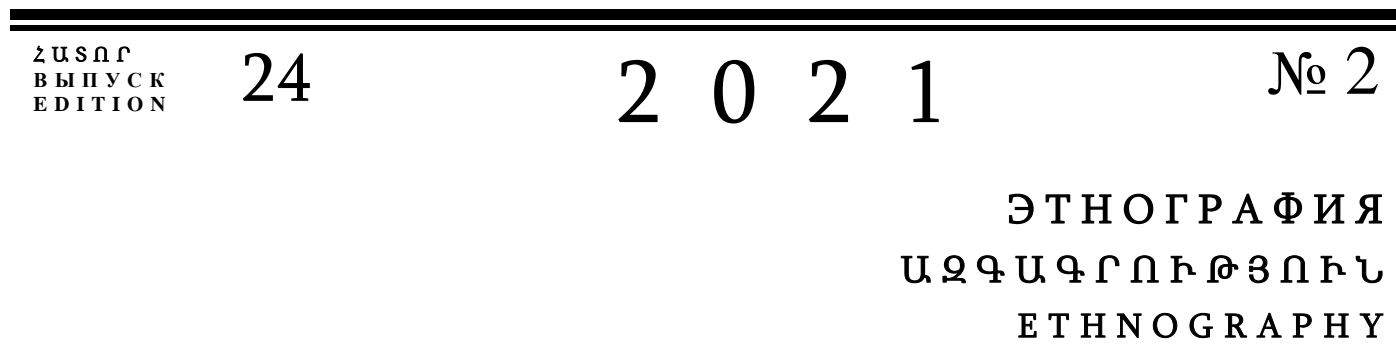

УДК: 93/94

DOI: $10.52971 / 18294316-2021.2-206$

\title{
НОСИТЕЛЬ ГУМАНИТАРНОГО ДУХА, ИЗУЧАЮЩИЙ МОБИЛЬНЫЙ ТЕХНО- (с учетом опыта А.А. Мартиросяна) \\ Фатимет Хуако
}

ФГБОУ ВО Майкопский государственный технологический университет

Ключевые слова: массовая культура, профессионализм, научное исследование, ручной сбор материала, интеллектуальный ресурс, вольность мыиления, неутомимый исследователь.

В статье в теоретическом аспекте рассматривается понятийная составляющая гуманитарного сведения, проводится обозначение имеющихся определений профессиональной составляющей, возможной в гуманитарной среде. На указанном понятийном материале, с учетом опыта научного исследования Арутюна Мартиросяна, назначается и выводится ряд присущих гуманитарному исследователю профессиональных качеств.

Введение: Но там, где всегда была обращенность к человеку (гуманизация), неизменно имела место быть и ее утрата, то есть дегуманизация. И потому в современном мире также нередко можно услышать констатацию второго из названных явлений. Однако еще не до конца ясно, что именно обозначает данное понятие, на почве чего продолжают вестись исследования. К примеру, одним из ученых уже текущего века И. Бубновой в связи с этим осуществлен эксперимент на уточнение определенных ассоциаций. Он был нацелен на выявление мощи влияния текущих ТВ- проектов на восприятие и ход мыслей сегодняшних РФ-граждан. Благодаря такому ассоциативному эксперименту, максимальный отрицательный фактор распространения массовой культуры был утвержден в качестве частого ослабителя для персонального языкового инструментария,а также-усилителя в сознании индивида мыслей, разнящихся с установками этносов. В связи с этим, на научной ниве появляется не до конца разработанная проблема глубокого изучения культур разных этносов и представленных ими цивилизаций. Применительно к родной ему армянской культуре эту проблему подчеркивал академический исследователь советского времени Арутюн Мартиросян, творческой активности которого посвящена сегодняшняя конференция. Он говорил: «Проблема создания глубоко обоснованной и максимально аргументированной периодизации культуры 
древней Армении остается до сих пор слабо разработанной» ${ }^{1}$. Соответственно происходящей сегодня технократической атаке следует подчеркнуть духовную упущенность идущих процессов и их результатов, каковые уже не первый год констатируются разнонаучными направлениями. Так, в частности, и решение указанной в цитате научной задачи А.А. Мартиросян видел в возможном слиянии исследовательских усилий тех же разных наук: «Решение этой проблемы является важнейшей задачей археологов Армении и требует объединения усилий коллектива специалистов гуманитарных, естественных и точных наук»².

При этом последовательное прогрессирование всякой деятельностной среды должно отличаться уровнем постоянно подтверждаемого профессионализма участников. А этот неизменно поддерживаемый профессионализм предполагает со стороны индивида постоянное и неустанное постижение мировых реалий. Причем индивид, являясь неким определенным творением цивилизации, задается познанием безбрежной вселенной лишь в определенном контексте, лишь в некой замкнутой (как хроникально, так и территориально) точке зрения. Так, к примеру, рассуждая о целевой заданности своей монографии «Армения в эпоху бронзы и раннего железа» (Ереван, 1964) А.А. Мартиросян не забывает честно признаться в недостаточной разработанности проблемы. Констатируя собственное неимение какого-либо притязания к полноценному разрешению перечня вопросов, он объясняет эту нерешенность так: последствиями «слабой изученности стратиграфически сложных, многослойных памятников, с четкой последовательностью культурных напластований, недостаточно полной проверки материала новейшими методами современной науки и, прежде всего, вследствие неравномерности изучения памятников различных периодов» ${ }^{3}$. При этом очевидным проявлением постоянной нацеленности на неизведанное, личностной иллюстрированности постигаемого и уверенности в нем выступает наука. Непосредственно такой закон наукообразности и насыщенности научным знанием допускает не просто применение научного материала в текстах учебников и в учебных программах. Налицо здесь также строгое требование введения в учебный процесс компонентов научного исследования, с обоснованием и проработкой его стадий.

Обнаружение смысла, выступающего как значимое в реальности событие, есть условный продукт интенсивного механизма, работающего на постижение беспредельного и всеохватного. Так, в частности, классический исследователь науки как понятия Майкл Полани, подчеркивает, что она «...несет в себе некое общее представление о природе вещей, являющееся для любознательного ума неиссякаемым источником догадок и предположений» ${ }^{4}$. Однако названный венгерский исследователь не переставал разделять найденное знание посредством личностного компонента, максимально присущего гуманитарным и минимального в науках точных. По сути, на сегодняшний день в такой внутри- научной градации общепринятым гуманитарием является некий интеллектуал, могущий найти ответ на любой словесный вопрос. Ему присущ индивидуальный, порой весьма своеобычный подход к культурам и историям многих цивилизаций. В случае появления в его поле зрения вывода либо заключения другого мыслителя носитель гуманитарного знания моментально проводит сопоставление и обнаруживает аналогию с отечественной научной мыслью. В силу собственной отвлеченности от технического мира он нередко страшится технических средств и предпочитает ручной сбор материала, может обратиться к печатному источнику в

\footnotetext{
${ }^{1}$ Мартиросян А. А. Армения в эпоху бронзы и раннего железа. Ереван. Изд-во АН Арм.ССР.1964.c.7.

${ }^{2}$ Там же.

${ }^{3}$ Там же.

${ }^{4}$ Полани М. Личностное знание. На пути к посткритической фиософии. М.: "Прогресс". -1985. с. 317.
} 
ущерб сайт- информации и не всегда способен понять, почему так мало представителей новых поколений стремятся обратиться к тем возвышенным ценностям, каковые культивировались его веком.

В случае постоянного, доказываемого нами выше, стремления к постижению обязательным обстоятельственным фактом выступает ценная сегодня вольность мышления, позволяющая индивиду окунуться в суть собственного существования. Такая вольность в модерн- идеологиях либерально-демократических систем выступает не просто импульсом, но и требованием, и компонентом реализации мысли в жизни социума.Одновременно при этом духовный компонент, сопровождающий процессы научного постижения, оказался на сегодня весьма замкнут образовательной сферой высшей школы, собравшей под своим навесом преобладающее число интеллектуальных представителей социума. Как высказывался по поводу свободы мыслительных операций известный отечественный литературовед и мэтр философии Михаил Эпштейн, «Свобода и свобода воли - синергетический результат формирования и развития личности (синергетического результата развития культуры), реализует возможность прорыва, трансцендирования в иное, потенцирования реальности» ${ }^{5}$. И именно при наличии масштабного и доступного интеллектуального ресурса человек способен все активнее и спокойнее, с большей уверенностью в себе продуцировать новые, востребованные социумом мысли. Соответственно этому постижение неизведанного в науке допустимо называть натуральной областью создания и оформления мастера-специалиста, не только несущего в своем характере трудовые навыки, но и искренне увлекающегося ими. Тем самым налицо именно личностный компонент и его воспитываемая среда.

На самом деле, сегодняшний индивид встречается посредством навязываемого ему персонализированного и коллективного подходов фактически с огромной глыбой шаблонных предметных, событийных, портретных моделей, предполагающих столь же стандартный реактивный эффект с его стороны. Кроме того, в распоряжении инициаторов и инвесторов подобных заданных макетов обязательно окажется распоряжение ходом мысли получателя. В частности, применительно к науке, такой ход подразумевает формулирование «заданного объекта», поиск и провозглашение «требуемой среды», а также утверждение «доступного теоретического и практического поля». И потому вполне закономерно, когда еще мало сформированные в своем возрасте юноши и девушки, имеющие весьма небогатый жизненный опыт, принимаются за формулирование собственных убеждений посредством идущих с экранов языковых принципов и словосочетаний. Однако именно с целью отступления от подобной негативной заданности, как раз для обнаружения своеобразных идентичных кадров, принадлежащих культуре рассматриваемой им эпохи, т.е. «для создания самой основы исследования» А.А. Мартиросян применяет наиболее популярный среди историков традиционный практический способ. «Наряду с опубликованными и изученными в какой-то степени материалами, автор вводит в научный оборот целый ряд не исследованных и не опубликованных ранее археологических комплексов» ${ }^{6}$.

Это успешно позволяет ученому уйти от заданности и углубить изученность, реализуя собственную личную ответственность исследователя. Профессионалом вообще чаще всего называется индивид, соответствующий присущими ему чертами и умениями требованиям занимаемой им должности и исполняемой им деятельности. Способный учитывать имеющиеся в социуме требования, а также, в лучшем случае, оперативно реагировать на

${ }^{5}$ Полани М. Личностное знание. На пути к посткритической фиософии. с. 317.

${ }^{6}$ Мартиросян А. А. Армения в эпоху бронзы и раннего железа. Ереван. Изд-во АН Арм.ССР.1964.c.7. 
них, индивид признается в социуме «профессионально подкованным». Именно посредством данного критерия обозначается в социуме ответ на вопрос о том, кому именно может принадлежать информационный и справочный авторитет, чья мысль выступит как аргумент либо как подсказка к какому-либо сомнительному жизненному пункту. Относительно данного критерия индивид зависим от собственной активности, устроенности и авторитета. Профессиональный уровень, личная ответственность производителя за производимые им продукты применимы и в научной среде. Отнюдь не индивид формулирует ответственность, а именно несомая и соблюдаемая им ответственность достаточно интенсивно структурирует, сильно задает индивида. И потому А.А. Мартиросян в случае собственного анализа в предисловии указанной монографии не забывает обозначить и имеющиеся в своей работе недостатки (к примеру, малая освещенность отдельных пунктов исторического пути), выводя, объясняя их негативные последствия так: это «приводит к частичной непропорциональности отдельных параграфов работы и к некоторому нарушению стройности изложения» ${ }^{7}$.

В обнаруживаемой нами содержательной составляющей, присущей возможному носителю гуманитарного знания, можно подчеркнуть, тем самым, особую развитость как профессиональных,так и личностных характеристик. В характере развитого гуманитария, таким путем, сосредоточены не только трудовые черты, почитаемые конкретным коллективом и социумом, однако и поисковые позывы, благостно нарушающие заданные стереотипы.

Bblвoдb: По сути гуманитарный специалист, выступающий неутомимым исследователем избранного вопроса, является искусным мастером своего дела, мудрым аналитиком, проверенным интеллектуалом персональной отрасли, реальным экспертом на профессиональной ниве. И потому интересующий нас сегодня в качестве такого примера А.А. Мартиросян в ходе рассмотрения и подбора источников при написании указанной нами выше монографии «старался уяснить целый ряд вопросов культуры древней Армении прежде всего для себя и надеялся тем самым принести пользу своим коллегам, учащейся молодежи, начинающим археологам и любителям археологии Армении» ${ }^{8}$ [1: 7]. Тем самым, налицо здесь вполне закономерная мотивация: и поисковое стремление, и личное желание принести пользу, выступающие в синхронной гармонии, доступной любому профессиональному представителю гуманитарного духа.

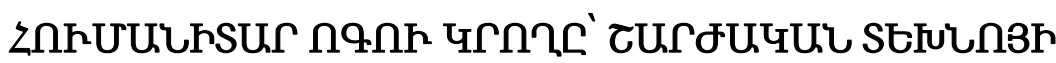

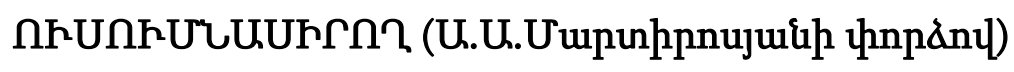 \\ Znıulqn \$.}

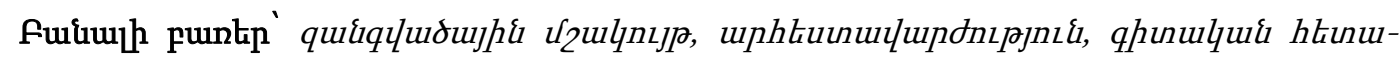

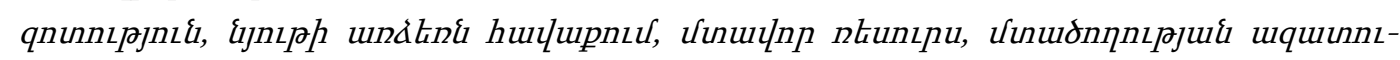

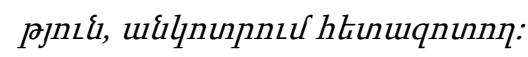

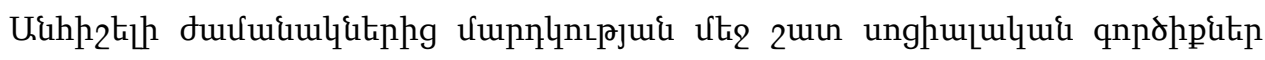

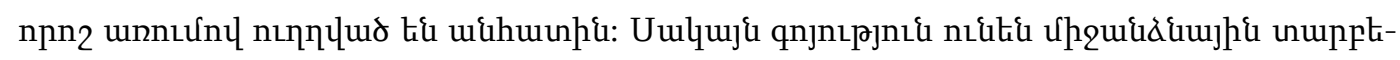

\footnotetext{
${ }^{7}$ Мартиросян А. А. Армения в эпоху бронзы и раннего железа. с. 7.

${ }^{8}$ Там же.
} 


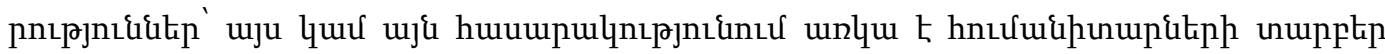

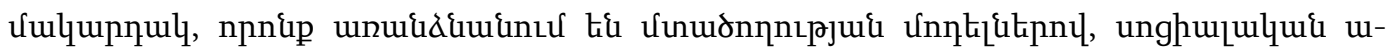

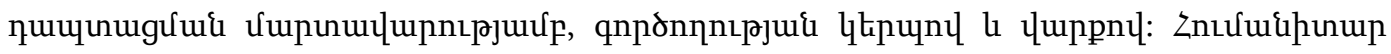

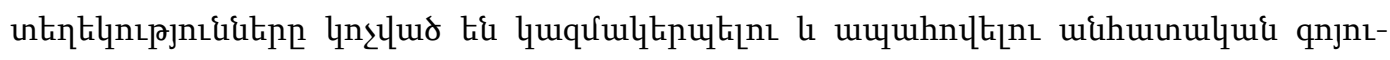

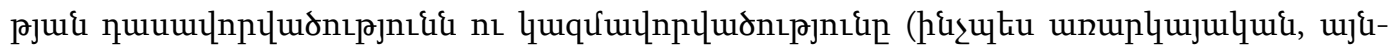

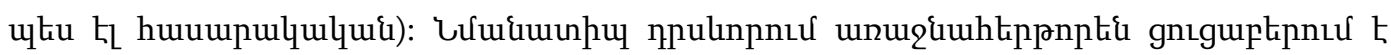

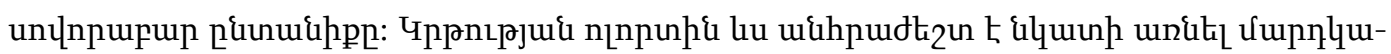

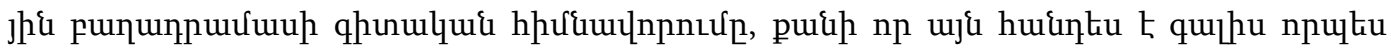

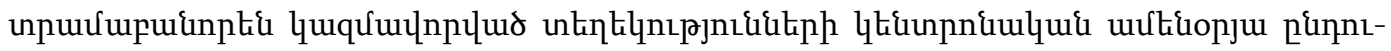

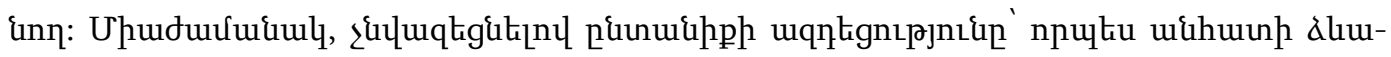

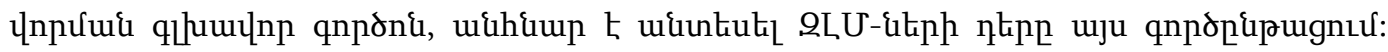

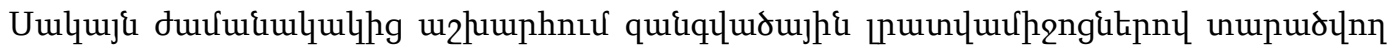

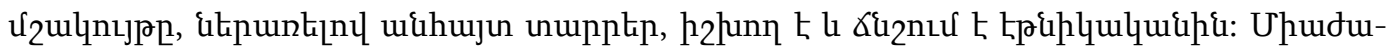

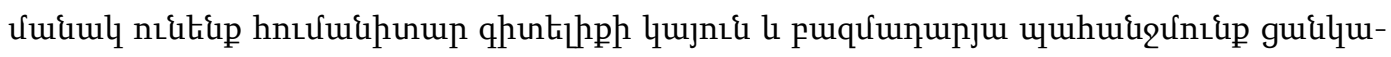

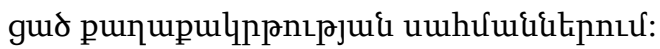

\section{BEARER OF THE SPIRIT OF HUMANITY- RESEARCHER OF MOBILE TECHNO (by experience of A.A. Martirosyan)}

\section{Huako F.}

Key words: mass culture, professionalism, scientific research, manual collection of material, intellectual resource, freedom of thought, unbreakable researcher.

From time immemorial in the human world, many social tools are to some extent directed at the individual. There are still interindividual differences here: there are different levels of humanitarians in this or that society, with various mental models, tactics of social adaptation, modes of action and behaviour. Humanitarian information strives to organize and guarantee the arrangement, the smoothness of individual existence (both material and social). The family usually plays the same role in the first place. The sphere of education also showed its need for scientifically grounded accounting of the human component, since it usually acted as the central, everyday recipient of reliable, logically verified and structured information. At the same time (without underestimating family influence, which is the central factor in the formation of an individual), it is impossible to stress the role of influence in this process of media environment. However, in the modern world, the culture disseminated through the media sometimes acts as an abundant resource for the presentation of unknown cultural dominants that frighten domestic ethnic groups. Thus, there is a steady and centuries-old demand for humanitarian knowledge within any civilization. 


\section{Б и б ли о гр а фия}

1. Мартиросян А. А. Армения в эпоху бронзы и раннего железа. Ереван. Изд-во Академии наук Арм. CCP. -1964.

2. Полани М. Личностное знание. На пути к посткритической фиософии. М. «Прогресс». -1985.

3. Эпштейн М. Философия возможного. Санкт-Петербург. Издательство «Алетейя». -2001.// http://www.emory.edu/INTELNET/fv0.html

Принята: 22.06. 2021

Реиензирована: 03.10. 2021

Сдана в пч.: 15.10 .2021

\section{Информащия об́ авторе:}

Фатимет ХУАКО: доктор филологических наук, профессор

Майкопского государственного технологического университета

E-mail: fatimah2@mail.ru3 